This article was downloaded by: [Cokely, Edward]

On: 4 March 2010

Access details: Access Details: [subscription number 919663466]

Publisher Taylor \& Francis

Informa Ltd Registered in England and Wales Registered Number: 1072954 Registered office: Mortimer House, 3741 Mortimer Street, London W1T 3JH, UK

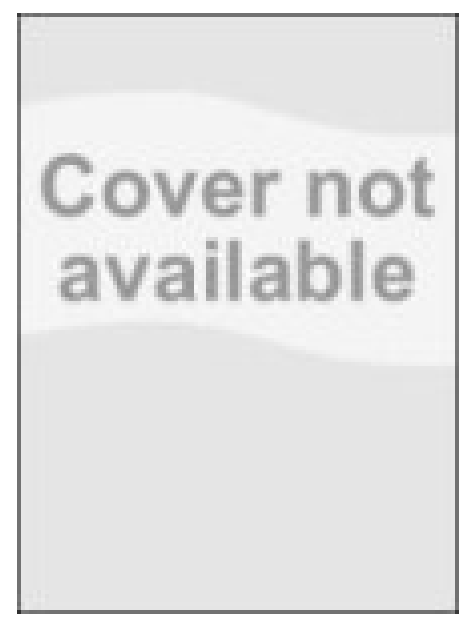

Encyclopedia of Library and Information Sciences, Third Edition

Publication details, including instructions for authors and subscription information:

http://www.informaworld.com/smpp/title $\sim$ content=t917508581

\title{
Information Use for Decision Making
}

Edward T. Cokely ${ }^{\text {a; }}$ Lael J. Schooler ${ }^{\text {a; }}$ Gerd Gigerenzer ${ }^{\text {a }}$

${ }^{a}$ Center for Adaptive Behavior and Cognition, Max Planck Institute for Human Development, Berlin,

Germany

Online publication date: 09 December 2009

To cite this Article Cokely, Edward T., Schooler, Lael J. and Gigerenzer, Gerd(2010) 'Information Use for Decision Making', Encyclopedia of Library and Information Sciences, Third Edition, 1: 1, $2727-2734$

\section{PLEASE SCROLL DOWN FOR ARTICLE}

Full terms and conditions of use: http://www.informaworld.com/terms-and-conditions-of-access.pdf

This article may be used for research, teaching and private study purposes. Any substantial or systematic reproduction, re-distribution, re-selling, loan or sub-licensing, systematic supply or distribution in any form to anyone is expressly forbidden.

The publisher does not give any warranty express or implied or make any representation that the contents will be complete or accurate or up to date. The accuracy of any instructions, formulae and drug doses should be independently verified with primary sources. The publisher shall not be liable for any loss, actions, claims, proceedings, demand or costs or damages whatsoever or howsoever caused arising directly or indirectly in connection with or arising out of the use of this material. 


\title{
Information Use for Decision Making
}

\author{
Edward T. Cokely \\ Lael J. Schooler \\ Gerd Gigerenzer \\ Center for Adaptive Behavior and Cognition, Max Planck Institute for Human Development, \\ Berlin, Germany
}

\begin{abstract}
How should we use information to make good decisions? Historically, the view has been that normatively superior decision making is the product of complex optimization processes that rationally consider and integrate all available information. Such optimization processes are well beyond the capabilities of mere mortals and in many cases are computationally intractable by any means. Fortunately, optimization processes are not always necessary: Less can be more. Simple decision processes-i.e., heuristics—used in the right environments enable fast, frugal, and adaptive decision making that can be as good as, or better than, even the most complex optimization processes. In what follows, we introduce research on ecological rationality and the science of adaptive heuristics. Our review includes 1) a brief history of the study of decision making; 2) a discussion of simple yet computationally precise heuristics, and how, when, and why they lead to superior performance; and 3) examples of how simple heuristics are starting to be used in the information sciences, such as in database literature prioritization or in the development of more user-friendly technologies. Although it may seem conventionally paradoxical, intelligent and adaptive information use often requires that information be ignored.
\end{abstract}

\section{INFORMATION USE FOR DECISION MAKING}

In the modern world, one of the leading causes of death is heart disease. As such it is easy to imagine that many people will search for information on its causes, symptoms, and treatments. But how will they search? One candidate is a keyword search in a search engine such as Google, which as of April 2008 returned about 35,500,000 "heart disease" results in less than $2 / 10$ of a second. This is not only a lot of information, it is too much information. Given the exponential rates of information growth in science and technology this number will likely continue to grow. ${ }^{[1]}$ Can people with limited knowledge, time, and computational capacities effectively search through vast amounts of information and make good decisions under conditions of high uncertainty? Can a scientific understanding of the cognitive processes involved in human information search and decision making help us improve information technology? In short, we believe the answer to both questions is yes.

To begin to illustrate our perspective, consider a recent study conducted by Michael Lee and his colleagues. ${ }^{[2]}$ Lee et al. compared the performance of a leading research database (i.e., PsycINFO) with the performance of two very different systems, each based on a model of human decision making. The first model was a "rational model" that attempted to combine all information in an optimal (or near-optimal) way. This model was inspired by what has traditionally been regarded as a normative theory of decision making. Relevance was determined using a
Bayesian learning algorithm allowing additive weighting and integration of all available information from cues such as authors, journals, keywords (title and abstract), language of the publication, and others. When some cue was associated (or unassociated) with a relevant article the probability that another article with that cue would be relevant (or irrelevant) was updated. Eventually, search was prioritized by selecting articles with "optimal" cue configurations as those of the highest relevance.

The second decision model developed by Lee et al. ${ }^{[2]}$ for the literature prioritization task used a rather different, perhaps even paradoxical process. In sharp contrast to a rational model, the one-reason decision-making model ignored a considerable amount of the available information in order to prioritize choices. This model, inspired by research on simple, adaptive heuristics ${ }^{[3]}$ used cues for inferring and assigning relevance, as did the rational model. However, in this case cues were first ordered by validity from most strongly associated and relevant to least relevant. Subsequently, a literature search prioritized results by selecting articles based solely on the most relevant cue that discriminated between options (for a more detailed discussion of validity, discrimination, cue ordering, and one-reason decision-making, see take-the-best later in this entry). Rather than attempting to integrate and use all possible sources of information, the one-reason decision-making model made choices based on a simple heuristic process (i.e., a rule of thumb), namely it prioritized results based only on the single most important cue that discriminated. 
To assess prioritization performance, Lee et al. ${ }^{[2]}$ compared both decision-making models (rational, one-reason) with the performance of PsycINFO. As expected, results indicated that all models returned relevant articles at above chance levels. More interestingly, and to some more surprisingly, the one-reason decision-making model consistently outperformed the rational model, which in turn outperformed PsycINFO. These results add to a growing body of evidence suggesting that more complex decision making processes do not necessarily provide superior decision-making performance. Instead, superior decision making can result from simple heuristic processes when used in the right environments.

So how is it possible that a simple heuristic was able to perform so well even when compared to a sophisticated optimization process? Part of the answer is that in our fundamentally uncertain world, simplicity often leads to robustness and efficiency. Heuristics improve performance by ignoring potentially misleading information. Heuristics also confer other benefits as this type of choice process tends be fast and efficient, relying on radically limited information search and decision rules. As well, in human, animal, and machine cognition, simple decision processes can be fine-tuned and can exploit the fit between our environmental task constraints and our available capacities, such as a human's limited attentional capacity and our adaptive ability to forget. ${ }^{[4-6]}$ In these ways and others, simple heuristics tend to produce and enable effective, adaptive judgment and decision making in many situations. $^{[3,7]}$

In this entry we will review a research program focused on adaptive behavior and cognition-or how simple heuristics, in the right environments, can make us smarter. Our entry will begin with a discussion of the history of decision-making theory and will then turn to issues of adaptive cognition, ecological rationality, and computational models of heuristics. Next, we will provide some examples of a few widely used heuristics. Finally, we close with a discussion of implications for the design of information-rich environments.

\section{Perspectives on Rationality: A Brief History}

The emergence of the modern debate on human rationality, or how people make decisions and what qualifies as a good decision, can be traced in large part to the Ages of Reason and Enlightenment (i.e., seventeenth and eighteenth centuries, respectively). During these times logic and careful, justifiable reasoning became highly prized by philosophers, empiricists, and political actors alike. As an example, consider the astronomer and physicist Pierre-Simon Laplace. Laplace's legacy includes seminal contributions to probability theory; however, more important for our purposes, he also provided a description of a fictional omniscient being that captured the Zeitgeist of the times. This being, known as Laplace's superintelligence, was envisioned as one who would know all the details of past and present and with this knowledge could readily make good choices and predict the future with perfect certainty. ${ }^{[8]}$

For many people, Laplace's vision of a decision maker who is omniscient and computationally unbounded may seem like an elaborate fantasy. Yet this fantasy or some version of it is fundamental to much of the research and theory in the modern decision sciences. Some readers will find this surprising, or ironically unreasonable, but models of "rational man" and homo economicus are among the most central and influential models used in decision science. According to neoclassical economic theory people behave as if they were unboundedly rational and make optimal (but not necessarily perfect) choices as if they had solved a complicated decision calculus. ${ }^{[9,10]}$ These decisions can be described by optimization processes that reflect people's maximization of their own subjective expected utilities (i.e., personal values) via multiattribute integration calculations. Such theories are at the core of dozens of models of decision making, including modern theories of motivation, attitudes, and moral judgments. ${ }^{[3,7]}$ However, even if this approach has provided interesting and useful theory, these models often conflict with empirical evidence. Psychological science has clearly demonstrated that this is not how real people with limited resources (i.e., time, attention, memory) use information to make decisions. ${ }^{[7,10-13]}$ Perhaps even more interestingly, these complicated and time-consuming processes are not even necessarily required for good, adaptive decision making. ${ }^{[3,7]}$

In the mid-twentieth century, Herbert Simon ${ }^{[14-16]}$ introduced his notion of bounded rationality. Simon argued that, among other things, people have only limited time, knowledge, and cognitive resources, and thus human decision makers cannot carry out the types of optimization computations that were (and still are) often assumed to underlie rational decision making. In part in reaction to Simon's notion of bounded rationality, a more modern version of a rational decision maker was developed by some decision researchers. The new theory, characterized by optimization under constraints, was once again concerned with a complex optimization calculus that could be used to make rational choices, but in these cases the optimization processes were also subject to any one of a number of constraints. ${ }^{[17]}$ To illustrate, in some models information search was necessary (i.e., no more omniscience) and so search processes were described and thus carried a cost. However, as a simplifying assumption the information search processes were often described by yet another optimization calculus wherein search was terminated according to the optimal cost-benefit ratio. As the number of constraints increases so too do the computational complexities of the search optimization functions that must be solved, even in simple decisions. In this way, optimization under constraints can be even more 
computationally demanding than what is required of the unboundedly rational agents. In efforts toward greater psychological plausibility, the optimization under constraints models created in some cases an even more psychologically unrealistic, and computationally unbounded, superintelligent decision maker. ${ }^{[17]}$

To be fair, although optimization models are not accurate process models of how real people make decisions, they do in some cases predict people's decisions or tell us about what outcomes or decisions should be favored. ${ }^{[18-20]}$ For these reasons, optimization models can be valuable tools. Nevertheless, optimization models are as-if models of human decision making: Many decision makers behave as if they use optimization processes even though they rely on other processes. ${ }^{[21-23]}$ Unfortunately, most research focusing on as-if models is essentially uninterested in and ill-equipped to understand the psychological dynamics involved in decision making. Hence, the as-if approach to modeling decision making leaves unanswered at least two crucial questions. First, how do people actually use information to make decisions? Second, given our known cognitive constraints (i.e., our bounded rationality), how is it that real decision processes can approximate and in some cases outperform optimization processes? To answer these questions, we turn to two different but related research programs that study human decision making and heuristics.

In the 1970s, Daniel Kahneman and Amos Tversky developed the heuristics and biases research program in cognitive psychology. ${ }^{[1,24,25]}$ This program was aimed at understanding how people actually make decisions. Toward this end researchers worked to reveal cognitive processes (i.e., heuristics) by focusing on judgment errors and "biases." However, in order to identify errors one must have normative assumptions (i.e., what is the appropriate standard for an accurate or good judgment), an issue that is not without controversy. ${ }^{[26,27]}$ In the case of the heuristics and bias approach, it was assumed that human cognition should be compared to a very specific set of rational, normative standards such as the outcomes of optimization processes and logic. Specifically, the heuristics and biases program searches for errors that are evidenced when people's judgments deviate from "an established fact... [or] an accepted rule of arithmetic, logic, or statistics" (p. 493). ${ }^{[28]}$ Indeed, it has demonstrated rather unequivocally that people do not reason in accord with content-blind logical laws or optimization processes, and that people often use heuristic processes for judgments and decisions. ${ }^{[10,29]}$ The research and findings on heuristics and biases have played key roles in shaping psychological and behavioral decision making research, contributing to the development of new research fields such as behavioral law and economics. ${ }^{[24,30]}$

In spite of its many successes, the heuristics and biases program has its limitations. One of our most serious concerns is that the program has emphasized ways in which heuristics are associated with errors, which has led some to an interpretation that heuristic use is a problem that needs to be corrected. In this light heuristics are seen as inferior choice processes designed to be used by computationally disadvantaged individuals. In contrast, other research demonstrates that heuristics (e.g., satisficing) are often powerful tools. ${ }^{[16,31,32]}$ As illustrated by the literature prioritization example in the introduction, in real-world environments these simple processes can enable adaptive decision making, matching or outperforming even the most sophisticated and time-consuming optimization processes.

\section{Ecological Rationality: Computational Models of Heuristics}

Consider for a moment a Darwinian inspired perspective on decision making. On this view, the goals and needs of organisms, such as finding food, securing mates, or protecting offspring, may or may not benefit from cognition that is logically coherent. For these organisms, fitness is best served when cognition can be tuned to ecological constraints. An organism's success will rely on the extent to which its cognition and behavior can benefit from and exploit features of its internal and external environment, regardless of how well these processes actually adhere to logical norms. An organism's ability to survive and reproduce depends on the fit between: 1) its evolved and developed capacities, 2) its cognitive processes, 3) and the structure of its natural environment. The analysis of the fit between capacities, processes, and environment is known as the study of ecological rationality.

Understanding the relationship between the mind and its environment serves as a starting point for the study of adaptive behavior and cognition. ${ }^{[32]}$ This adaptive framework has deep roots in psychology. For example, Herbert Simon has argued that "Human rational behavior is shaped by a scissors whose two blades are the structure of task environments and the computational capabilities of the actor" (p. 7). ${ }^{[16]}$ If one wants to understand how people make judgments and decisions, and why and when these processes work, one cannot examine only processes (as most psychologists do) or only environments (as most economists and sociologists do). Studying how one scissor blade cuts, or fails to cut, does not tell us how, why, or when the scissors will actually work.

In concert with the study of ecological rationality, a second key concept for the research program on adaptive behavior and cognition is the adaptive toolbox. This adaptive toolbox is conceived of as a collection of precisely defined cognitive heuristics and other adaptive processes that can be used both consciously and unconsciously (e.g., intuitively) to solve problems in the real world. Organisms use a number of specific tools that are well-suited to certain task environments, not entirely unlike specific wrenches and screwdrivers that are designed for specific chores. In this way, there is no general all-purpose heuristic (or optimization calculus) that can provide the best 
solution for every judgment or decision. In contrast, heuristic application is more narrow and constrained, although many heuristics can be used more or less effectively across a range of situations (e.g., a screwdriver can also be used to open a can of paint). Perhaps most critically, by defining heuristics as formal computational models, one can then identify (e.g., via simulations) exactly when, how, and why certain heuristics will succeed or fail. Theoretically, this collection of adaptive heuristics provides a precisely defined, psychologically plausible alternative to as-if optimization models of human decision making.

So how is it that these simple heuristic processes can match and outperform complex optimization processes? The answer has at least two key parts. The first part has to do with computational tractability. Regardless of the extraordinary increases in computing power that we have enjoyed in recent years, for most decisions there simply is no optimization strategy that can be computed. ${ }^{[3]}$ Optimization, except in radically simplified environments, is largely computationally intractable. Even simple problems turn out to be so complex as to be impenetrable to optimization techniques. This is true of problems that are well-defined such as in games like Chess or Go, as well as for the many ill-defined problems we face in the modern world such as choosing an outfit, a dinner, a career, or a spouse. In all of these cases, heuristic processes are not only valuable but they are absolutely essential.

The second reason heuristics can perform well is that they are robust and reduce the chance of fitting noise in our environment (i.e., overfitting). Because we live in a fundamentally uncertain world, information in our environment (i.e., environmental signals) consists, of both reliable and unreliable content (i.e., noise), or in other words, information that is diagnostic and information that could lead us astray. Particularly in situations that involve high uncertainty, the trick for intelligent decision making is to ignore information, such as seemingly informative but ultimately irrelevant information (e.g., past performance of stocks for predicting changes in valuation). If we performed an optimization calculation for every decision that included every regularity from every previous situation, our ability to accurately predict outcomes in new environments would be crippled as it would be based on many kinds of random, non-diagnostic noise. In contrast, because heuristics are simple and exploit cognitive capacities such as our adaptive capacity for forgetting ${ }^{[4]}$ we can reduce the risk that we will overfit non-diagnostic environmental signals. Moreover, because adaptive heuristics rely on a limited search of the available information there is a good chance that they will avoid most sources of the random noise while still benefiting from a focus on the most reliable sources of information. ${ }^{[33]}$

In addition to the performance benefits noted above adaptive heuristics confer at least one more set of ecologically important advantages: Heuristics can provide fast and frugal decision making. Because heuristics can exploit our capacities (both evolved and developed), such as our remarkable capacity for highly accurate recognition memory, the time and energy needed for these decision processes are minimized. Heuristics provide essential competitive advantages (e.g., minimizing time, search, effort invested) whether one is making decisions in the wild or in the boardroom. This frugality may benefit us physiologically as our brain, which is roughly $2 \%$ of our overall mass, commonly requires between $15 \%$ and $25 \%$ of our daily energy and oxygen budget. Even simple acts of deliberative, effortful processing can significantly influence and deplete our energy stores. ${ }^{[34]}$ In these ways and others simple heuristics tend to enable adaptive decisions in ecological environments.

\section{Heuristic Building Blocks}

Advances in the science of adaptive behavior and cognition rely in large part on identifying and modeling exact heuristic processes. These processes are described by dividing heuristics into different building blocks (i.e., subprocesses), often including: 1) search processes, 2) stopping rules, and 3) decision rules, which are composed of either unique processes or nested combinations of other more basic heuristics. Consider the take-the-best heuristic. ${ }^{[34]}$ Take-the-best belongs to a family of one reason decision-making heuristics and has proven itself to be a common and effective decision tool. Take-the-best can be used when one is faced with a choice between two different options. In these cases, take-the-best orders and considers different cues (reasons) for making its decision by selecting the best option with the first cue that discriminates between the options. In simpler language, consider a preference situation in which one is trying to decide which of two colleges to attend. One way you could make a decision would be to focus on only a single factor, the one that seems most important. For some people that might be prestige, and thus when considering both Harvard and say San Francisco State University (SFSU), one would likely pick Harvard. However, if the most important consideration was which school was affordable, you might then select the public school (SFSU) where tuition is far less. In either case, the process is roughly the same and requires only a very minimum amount of search and reasoning. First identify and order the most important cues that you will use to decide and then make your choice based on the first discriminating cue (i.e., the first cue in which one option is clearly better than the other). Indeed, in investigations of real world choices such as the one described above (but also including multiple-cue inference tasks where there are known correct answers such as inferring which of two cities is larger) we see that people often make decisions with simple processes like take-the-best. ${ }^{[36,37]}$

More formally, take-the-best is made of three precisely defined building blocks including: 
1. Search rule: Search through the cues in order of their validity (correlation with criteria). Look up the cue values of the cue with the highest validity first.

2. Stopping rule: If one object has a positive cue value and the other does not (or is unknown), then stop search and proceed to Step 3. Otherwise, exclude the cue and return to Step 1. If no more cues are found, guess.

3. Decision rule: Predict that the object with the positive cue value has the higher value on the criterion.

Again, each of these rules precisely defines behavior, leads to a testable prediction, and therefore can be computationally modeled or evaluated empirically. Given this precision, researchers have also used mathematical analysis and simulations to tell us about the ecological rationality of heuristics, describing for example the environments wherein take-the-best will perform better and worse. ${ }^{[38]}$ To illustrate, one can analytically prove that take-the-best is associated with superior decision making in environments that have a non-compensatory cue structure. Any time the sum of the cue weights does not add up to the sum of the best (remaining) cue, take-the-best will perform very well. We might imagine a task of trying to model which libraries have experienced a budget growth of at least $10 \%$. In this example we will assume that the ecological validities (i.e., the relative frequency with which a binary cue correctly predicts the criterion) of the cues are one, one-half, one-fourth, and one-eighth, where lending rates of the library are the single most important factor (i.e., more lending is most strongly associated with strong growth), the current size of the library is one-half as important, and location is half again as important. In this case, the structure is non-compensatory because the sum of the cue weights can never add up to (or compensate for) the difference between the first cue (lending rates) and all other cues (Fig. 1). ${ }^{[39]}$ Even if one finds that another library is larger and is in the perfect location, etc., these factors could not compensate if that library had low lending rates. Findings such as these can tell us both when a simple heuristic will fail and when it will work better than or at least as well as more complex decision processes. These findings also allow for insights into what decision (or inference) should be made as well as what information should actually be used and ignored in the decision-making process.

\section{Two Memory-Based Heuristics}

Many heuristics benefit by taking advantage of evolved and developed capacities. In humans, some capacities are more fundamental than others, in the sense that they develop earlier and persist longer. Recognition memory is one such capacity. In many ways our recognition memory is much more sensitive and reliable than the vast majority

\section{Noncompensatory environment}

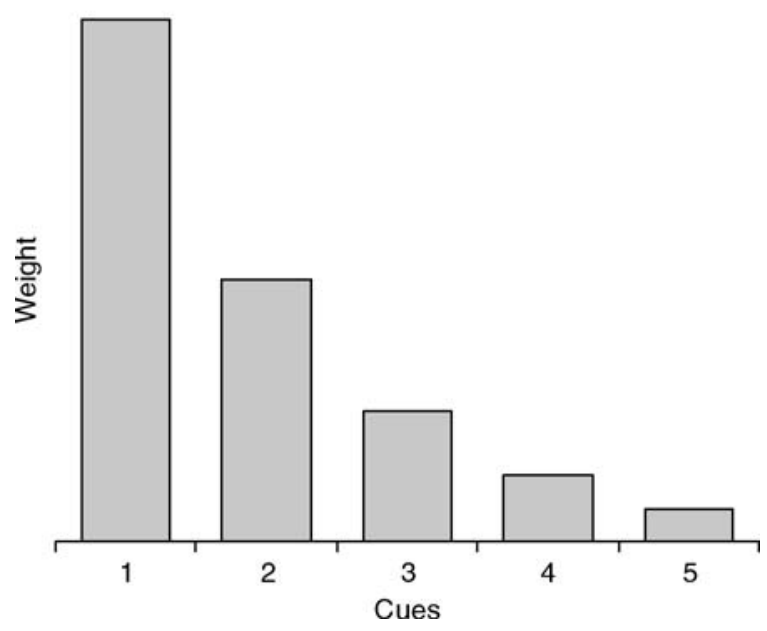

Fig. 1 A noncompensatory environment. In this environment one can see that the first (binary) cue will always make predictions that are always as accurate as any linear combination of all cues.

of other mnemonic processes, something that becomes increasing apparent as we age. To better appreciate this capacity we invite you to try an exercise: Do your best to recall the names of the seven dwarves from the story Snow White and the Seven Dwarves. Although many of us will have trouble recalling these characters' names nearly everyone, or at least most Americans, will immediately recognize them (Can you recognize the seven real dwarves in this list of nine: "Bashful," "Doc," "Sloppy," “Dopey," "Grumpy," "Pudgy," "Happy," "Sleepy," and "Sneezy"). As noted, recognition not only reflects a fundamental aspect of memory, it also provides a powerful cue for adaptive decision making.

Considerable research now demonstrates that when facing a choice people often rely on their recognition, or lack thereof, to help inform their inferences. This heuristic process has been formalized in the recognition heuristic, which is modeled as follows: "if one of two objects is recognized and the other is not, then infer that the recognized object has the higher value with respect to the criterion." [40] The interesting theoretical finding is that sometimes less is more, such that ignorance will actually improve our decision making in a variety of environments. Imagine for instance that your task is to select which of two stocks to invest in. One company might be named Coca Cola Company and the other Ameritech. One way to decide between the two companies is simply to invest in the company that is recognized and familiar. If you do this, and thus decide according to the recognition heuristic, you'd likely select Coca Cola. Although it is a simple strategy that relies largely on one's ignorance, research shows that it can match or outperform "expert" stock portfolios, in certain common environments ${ }^{[41,42]}$ (for boundary conditions see also Andersson). ${ }^{[43]}$ 
By way of analysis and computational modelling it is possible to understand the conditions in which recognition will be likely to provide good (and not so good) inferences. Research indicates that recognition will lead to good decisions whenever it is correlated with a decision criterion. Consider the task of trying to decide which of two cities is larger (in population), selecting between Detroit and Houghton (MI), for example. In this case, recognition may be diagnostic as cities that have more people are also more likely to be mentioned in the media and have more major sports teams, companies, airports, events, and so on. Bigger cities are therefore more likely to be recognized and not recognizing a city becomes a valuable basis for inference. Of course, recognition does not guarantee that one city is larger than another (e.g., Hollywood, CA, vs. Fresno, CA). However, when there is a strong correlation between recognition and the decision criteria, recognition will tend to provide accurate inferences.

The fluency heuristic ${ }^{[44,45]}$ is a second fundamental memory-based inference process (for a recent review see Kelley). ${ }^{[46]}$ Considerable converging evidence reveals that fluency, which is roughly defined as our subjective experience of the ease of information processing (cf. availability), often dramatically influences our confidence, judgment, and decision making. ${ }^{[24,25,47-49]}$ If we again consider the real-world task of selecting stocks we find that people tend to judge that unrecognized companies with names that are easier to read (pronounce) are more likely to be profitable. This is true in laboratory studies and can also be seen in actual stock trading during initial public offerings. ${ }^{[50,51]}$ Indeed, there is a long tradition of studying fluency and availability. Here we focus on more recent research done within the adaptive framework. Specifically, we have developed the ACT-R fluency heuristic that formalized: "If one of two objects is more fluently processed, then infer that this object has the higher value with respect to the criterion" (p. 612) ${ }^{[4]}$ In this case, fluency is precisely defined as the speed with which declarative memory chunks can be retrieved in the computational cognitive architecture ACT-R. As with the recognition heuristic and take-the-best, the ACT-R fluency heuristic relies on a simple but powerful one reason decision-making process. The critical difference is not whether or not one recognizes some bit of information but how quickly and easily one recognizes it. The more easily one option is recognized the more likely it is to influence our decision, a process that is fundamental to a variety of adaptive inferences. Understanding these processes provides insight into the adaptive nature of our cognitive architecture. More generally, understanding the processes used by one of the most complex and efficient adaptive devices known-i.e., the human mind — can help enable the design of better innovative engineering and information technology solutions. ${ }^{[52]}$

\section{Heuristics, Usability, and Environmental Design}

The work of Lee et al. ${ }^{[2]}$ on search prioritization serves as an excellent example of the potential for using adaptive heuristics to improve information technology. However, this is only one side of the usability issue. Opportunities also exist to study user decision making to further understand the heuristic processes commonly relied upon in database and library type environments. Currently there is a small but growing body of work using process-oriented or otherwise ecologically grounded approaches that may be valuable for future research efforts. ${ }^{[53,54]}$ For example, some research focuses on variations in human search strategies in database environments ${ }^{[55]}$ such as differences in the processes of children and adults (Bilal and Kirby, 2002). ${ }^{[61]}$ In these studies, key results indicate that specific information search strategies can be identified that tend to systematically vary with age. Similarly, there is a somewhat more developed tradition of studying human search behavior in general consumer choices that has begun to explore Internet or database-type environments. ${ }^{[57-59]}$ These studies have also been successful in identifying search strategies, with some going a step further and identifying stopping rules and the environmental constraints that mediate heuristic selection. ${ }^{[60]}$ For instance, Browne et al. have started to identify the relationships between environmental factors and search processes, suggesting that there often exists a positive relationship between task complexity, search times, and stopping rules. Similarly, other recent work has used our understanding of human decision-making heuristics to improve human-computer interface design. By eliminating non-diagnostic or highly redundant (correlated) product-attribute information researchers limit the redundant search processes of users, which allows consumers to better cope with information overload effects including the so-called too much choice effect. ${ }^{[62]}$

There are also a number of other connections between specific heuristics and library and information search behaviors that have yet to be explored. As noted, both recognition and fluency tend to influence everyday choices. In a library environment it is easy to imagine that these heuristics would influence decisions such as which book(s) to order or read (e.g., an author is recognized, an author is more quickly recognized); what search queries to use (e.g., do you recognize any results from these keywords); and when to stop searching (e.g., when further search yields little in the way of relevant recognizable information; stop search when information is no longer easily recognized or fluent). However, these simple connections and the review provided here can only serve as an introduction. There are many other heuristics and aspects of information use and search processes that may prove to be very influential in the design of user-friendly technology (for a more complete overview see Gigerenzer). ${ }^{[7,32]}$ 


\section{CONCLUSION}

Over the last few decades there has been considerable focus on the fact that people often use heuristics to make decisions. Fortunately, in the right environment these simple heuristic processes make us smart by simplifying and speeding decisions, and by helping us ignore irrelevant information. In our complex and uncertain world simple heuristics sometimes represent the very best decision making processes available. Whether designing better information technology, better decision support systems, or better decision environments one lesson is clear: Superior decision making does not necessarily require more complex processes. Less can be much more. In these ways and others, the future holds great opportunities and promise for engineering simplicity.

\section{REFERENCES}

1. Egghe, L.; Rao, I.K.R. Classification of growth models based on growth rates and its applications. Scientometrics 1992, 25, 5-46.

2. Lee, M.D.; Loughlin, N.; Lundberg, I.B. Applying one reason decision-making: The prioritisation of literature searches. Aust. J. Psychol. 2002, 54 (3), 137-143.

3. Gigerenzer, G.; Todd, P.M.; and the ABC Research Group. Simple Heuristics That Make Us Smart; Oxford University Press: Oxford, 1999.

4. Schooler, L.J.; Hertwig, R. How forgetting AIDS heuristic inference. Psychol. Rev. 2005, 112, 610-628.

5. Anderson, J.R.; Schooler, L.J. Reflections of the environment in memory. Psychol. Sci. 1991, 2, 396-408.

6. Schooler, L.J.; Anderson, J.R. The role of process in the rational analysis of memory. Cogn. Psychol. 1997, 32 (3), 219-250.

7. Gigerenzer, G.; Selten, R., Eds. Bounded Rationality: The Adaptive Toolbox; MIT Press: Cambridge, MA, 2001.

8. Gigerenzer, G. Bounded and rational. In Contemporary Debates in Cognitive Science (Contemporary Debates in Philosophy No. 7); Stainton, R.J., Ed.; Blackwell: Oxford, U.K., 2006.

9. Hastie, R. Problems for judgment and decision making. Annu. Rev. Psychol. 2001, 52, 652-683.

10. Shafir, E.; Tversky, A. Decision making. In Thinking; Smith, E.E., Osherson, D.N., Eds.; MIT Press: Cambridge, MA, 1995; Vol. 3.

11. Kahneman, D.; Slovic, P.; Tversky, A. Judgment under Uncertainty: Heuristics and Biases; Cambridge Press: New York, 1982.

12. Payne, J.W.; Bettman, J.R.; Johnson, E.J. Behavioral decision research-A constructive processing perspective. Annu. Rev. Psychol. 1992, 43, 87-131.

13. Payne, J.W.; Bettman, J.R.; Johnson, E.J. The Adaptive Decision Maker; Cambridge University Press: Cambridge, U.K., 1993.

14. Simon, H.A. Rational choice and the structure of the environment. Psychol. Rev. 1956, 63, 129-138.
15. Simon, H.A. Models of Man: Social and Rational; Willey: New York, 1957.

16. Simon, H.A. Invariants of human behavior. Annu. Rev. Psychol. 1990, 41, 1-19.

17. Sargent, T.J. Bounded Rationality in Macroeconomics; Oxford University Press: New York, 1993.

18. Chater, N.; Oaksford, M. Ten years of the rational analysis of cognition. Trends Cogn. Sci. 1999, 3 (2), 57-65.

19. Chater, N.; Oaksford, M.; Nakisa, R.; Redington, M. Fast, frugal, and rational: How rational norms explain behavior. Organ. Behav. Hum. Decis. Process. 2003, 90 (1), 63-86.

20. Chater, N.; Tenenbaum, J.B.; Yuille, A. Probabilistic models of cognition: Conceptual foundations. Trends Cogn. Sci. 2006, 10, 287-291.

21. Brandstätter, E.; Gigerenzer, G.; Hertwig, R. The priority heuristic: Making choices without trade-offs. Psychol. Rev. 2006, 113 (2), 409-432.

22. Weber, E.U.; Johnson, E.J.; Milch, K.F.; Chang, H.; Brodscholl, J.C.; Goldstein, D.G. Asymmetric discounting in intertemporal choice-A query-theory account. Psychol. Sci. 2007, 18, 516-523.

23. Cokely, E.T.; Kelley, C.M. Cognitive abilities and superior decision making under risk: A protocol analysis and process model evaluation. Judgement and Decision making. 2009, 4, 20-33.

24. Kahneman, D.; Tversky, A., Eds. Choices, Values and Frames; Cambridge University Press and the Russell Sage Foundation: New York, 2000.

25. Tversky, A.; Kahneman, D. Judgment under uncertainty: Heuristics and biases. Science 1974, 185, 1124-1130.

26. Anderson, J.R. Is human cognition adaptive? Behav. Brain Sci. 1991, 14 (3), 471-484.

27. Gigerenzer, G. On narrow norms and vague heuristics: Reply. Psychol. Rev. 1996, 103, 592-596.

28. Kahneman, D.; Tversky, A. On the study of statistical intuitions. In Judgment under Uncertainty: Heuristics and Biases; Kahneman, D., Slovic, P., Tversky, A., Eds.; Cambridge University Press: Cambridge, U.K., 1982.

29. Kahneman, D. A perspective on judgment and choiceMapping bounded rationality. Am. Psychol. 2003, 9, 697-720.

30. Gigerenzer, G.; Engel, C., Eds. Heuristics and the Law; MIT Press: Cambridge, MA, 2006.

31. Gigerenzer, G. Fast and frugal heuristics: The tools of bounded rationality. In Handbook of Judgment and Decision Making; Koehler, D., Harvey, N., Eds.; Blackwell: Oxford, U.K., 2004.

32. Gigerenzer, G.; Brighton, H. Homo heuristicus: why biased minds make better inferences. Topics in Cognitive Sciences. 2009, 1, 107-143.

33. Brighton, H.; Gigerenzer, G. Bayesian brains and cognitive mechanisms: Harmony or dissonance? In The Probabilistic Mind: Prospects for Rational Models of Cognition; Chater, N., Oaksford, M., Eds.; Oxford University Press: Oxford, U.K., 2007.

34. Gailliot, M.T.; Baumeister, R.F. The physiology of willpower: Linking blood glucose to self-control. Pers. Soc. Psychol. Rev. 2007, 11, 303-327.

35. Gigerenzer, G.; Goldstein, D.G. Reasoning the fast and frugal way: Models of bounded rationality. Psychol. Rev. 1996, 103, 650-669. 
36. Galotti, K.M. Decision structuring in important real-life choices. Psychol. Sci. 2007, 18 (4), 320-325.

37. Dhami, M.K. Psychological models of professional decision making. Psychol. Sci. 2003, 14, 175-180.

38. Katsikopoulos, K.V.; Martignon, L. Naive heuristics for paired comparisons: Some results on their relative accuracy. J. Math. Psychol. 2006, 50, 488-494.

39. Martignon, L.; Hoffrage, U. Why does one-reason decision making work? A case study in ecological rationality. In Simple Heuristics That Make Us Smart; Gigerenzer, G., Todd, P.M., the ABC Research Group, Eds.; Oxford University Press: New York, 1999; 119-140.

40. Goldstein, D.G.; Gigerenzer, G. Models of ecological rationality: The recognition heuristic. Psychol. Rev. 2002, 109, 75-90.

41. Borges, B.; Goldstein, D.G.; Ortmann, A.; Gigerenzer, G. Can ignorance beat the stock market? In Simple heuristics that Make Us Smart; Gigerenzer, G., Todd, P.M., the ABC Research Group, Eds.; Oxford University Press: New York, 1999.

42. Ortmann, A.; Gigerenzer, G.; Borges, B.; Goldstein, D.G. The recognition heuristic: A fast and frugal way to investment choice? In Handbook of Experimental Economics Results: Vol. 1 (Handbooks in Economics No. 28); Plott, C.R., Smith, V.L., Eds.; North-Holland: Amsterdam, 2008; 993-1003.

43. Andersson, P.; Rakow, T. Now you see it now you don't: The effectiveness of the recognition heuristic for selecting stocks. Judgment Decis. Making 2007, 2, 29-39.

44. Jacoby, L.L.; Brooks, L.R. Nonanalytic cognition-memory, perception, and concept-learning. Psychol. Learn. Motiv. Adv. Res. Theory 1984, 18, 1-47.

45. Jacoby, L.L.; Dallas, M. On the relationship between autobiographical memory and perceptual learning. J. Exp. Psychol. Gen. 1981, 3, 306-340.

46. Kelley, C.M.; Rhodes, M.G. Making sense and nonsense of experience: Attributions in memory and judgment. In Psychology of Learning and Motivation: Advances in Theory and Research; Ross, B.H., Ed.; 2002; Vol. 41, 293-320.

47. Jacoby, L.L.; Kelley, C.; Brown, J.; Jasechko, J. Becoming famous overnight-Limits on the ability to avoid unconscious influences of the past. J. Pers. Soc. Psychol. 1989, $56,326-338$.

48. Jacoby, L.L.; Woloshyn, V.; Kelley, C. Becoming famous without being recognized-Unconscious influences of memory produced by dividing attention. J. Exp. Psychol. Gen. 1989, 118, 115-125.
49. Tversky, A.; Kahneman, D. Availability: A heuristic for judging frequency and probability. Cogn. Psychol. 1973, 5, 207-232.

50. Alter, A.L.; Oppenheimer, D.M. Predicting short-term stock fluctuations by using processing fluency. Proc. Natl. Acad. Sci. 2006, 103, 9369-9372.

51. Cokely, E.T.; Parpart, P.; Schooler, L.J. On the link between cognitive control and heuristic processes. In Proceedings of the 31st Annual Conference of the Cognitive Science Society, Taatgen, N.A., van Rijn, H., Eds.; Austin, TX: Cognitive Science Society, 2009; 2926-2931.

52. Pirolli, P.; Fu, W.T. SNIF-ACT: A model of information foraging on the world wide web. In Proceedings of the Ninth International Conference on User Modeling, Johnstown, PA, 2003.

53. Marewski, J.N.; Galesic, M.; Gigerenzer, G. Fast and frugal media choices. In Media Choice: A Theoretical and Empirical Overview, Hartmann, T., Ed.; Routledge: New York and London, 2009; 107-128.

54. Van Maanen, L.; Marewski, J. N. Recommender systems for literature selection: A competition of decision making and memory models. In Proceedings of the 31st Annual Conference of the Cognitive Science Society, Taatgen, N.A., van Rijn, H., Eds.; Austin, TX: Cognitive Science Society, 2009; 2914-2919.

55. Thatcher, A. Information-seeking behaviours and cognitive search strategies in different search tasks on the WWW. Int. J. Indus. Ergon. 2006, 36, 1055-1068.

56. Dresang, E.T. The information-seeking behavior of youth in the digital environment. Libr. Trends 2005, 54, 178-196.

57. Ozanne, J.L.; Brucks, M.; Grewal, D. A study of information search behavior during the categorization of new products. J. Consum. Res. 1992, 18, 452-463.

58. Guo, C. A review on consumer search: Amount and determinants. J. Bus. Psychol. 2001, 51, 505-519.

59. Zhang, J.; Fang, X.; Sheng, O.R.L. Online consumer search depth: Theories and new findings. J. Manage. Inform. Syst. 2006-2007, 23, 71-95.

60. Browne, G.J.; Pitts, M.G.; Wetherbe, J.C. Cognitive stopping rules for terminating information search in online tasks. Mis Quart. 2007, 31, 89-104.

61. Bilal, B.; Kirby, J. Differences and similarities in information seeking: Children and adults as Web users. Inform. Process. Manage. 2002, 38, 649-670.

62. Fasolo, Barbara; McClelland, Gray H; Todd, Peter M. Escaping the tyranny of choice: When fewer attributes make choice easier. Marketing. 2007, 7 (1). 13-26. 